\title{
Familial Background as a Hidden Cause for Obesity among College Going Girls
}

\author{
Anita Garg Mangla ${ }^{1 *}$, Neeru Dhamija ${ }^{1 *}$, Urvashi Gupta², Meenal Dhall² \\ ${ }^{1}$ Department of Biochemistry, Daulat Ram College, University of Delhi, Delhi, India \\ ${ }^{2}$ Department of Anthropology, University of Delhi, Delhi, India \\ Email: ^anitamangla@yahoo.com, ^neerudhamija@gmail.com
}

How to cite this paper: Mangla, A.G., Dhamija, N., Gupta, U. and Dhall, M. (2019) Familial Background as a Hidden Cause for Obesity among College Going Girls. Journal of Biosciences and Medicines, 7, 1-13. https://doi.org/10.4236/jbm.2019.74001

Received: February 25, 2019

Accepted: April 1, 2019

Published: April 4, 2019

Copyright (c) 2019 by author(s) and Scientific Research Publishing Inc. This work is licensed under the Creative Commons Attribution International License (CC BY 4.0).

http://creativecommons.org/licenses/by/4.0/

(c) (i) Open Access

\begin{abstract}
Background: Rapid changes in global economies and industrialization have resulted in switch from traditional diets and labor intensive lifestyle to consumption of modern calorie-rich diets loaded with fat and sugar contents, accompanied with sedentary lifestyle further leading to onset of numerous non-communicable, chronic disorders; obesity being one of them. This study aims at investigating risk posed by family history of obesity over the generations for inducing extreme overweight conditions among adolescent females of Delhi. Methods: Present work is a cross-sectional study conducted in Delhi (India) with sample size of 444 females aged between $18-22$ years. Socio-demographic aspect along with lifestyle-related profile of participants was assessed using a self-administered proforma. Prior history of obesity among family members, if any, was noted as well, and anthropometric and physiologic measurements were recorded using well established customary techniques. Analysis was carried out in SPSS 20.0. Results: Participants holding a history for obesity in family were comparatively more obese than their counterparts. Positive family history for the same has been found possessing a notably closer association with elevated levels of adiposity determined by various physical and physiological variables. Conclusion: Family history of excessive fatness develops high risk of pathological manifestation for the same in upcoming generations that needs to be administered effectively-at individual or population level, and addressed efficiently by one's family or by the prevailing governmental provisions.
\end{abstract}

\section{Keywords}

Obesity, Family History, Genetic Predisposition, Delhi, Behavioral Patterns

${ }^{\star}$ Both authors have contributed equally to the work and must be regarded as first authors and corresponding authors. 


\section{Introduction}

An important determinant of morbidity and mortality of people all over the world is non-communicable diseases. Non-communicable diseases have major consequences for people in all age groups all over the world. But it primarily involves adults, the most productive and active population, responsible for the economic and social welfare of both children and elderly people dependent on them [1]. There are studies that have illustrated an increased incidence of non-communicable, chronic maladies among the family members of patients who were themselves under distress with such diseases amongst different populations [1] [2] [3]. Different patho-physiological and metabolic changes, such as insulin insensitivity, higher levels of LDL and triglycerides, cardiac and renal morphological and functional changes qualitatively similar to those found among patients, can often be detected in the pre-disease phase. This highlights the need for early detection of the population at risk to initiate interventions in advance adopting anticipatory measures preventing progression of disease [1].

Obesity has surfaced as a major non-communicable health risk factor on a worldwide-scale, whereby much focus is now being shifted towards finding the environmental trigger and its prevention [4]. Lifestyle changes along with epigenetic mechanisms have been known to have indirect associations with metabolism and energy expenditure, thus aggravating proneness to lifestyle disorders, primarily obesity [5] [6]. It is well known and understood that the complex web of association among lifestyle, physical activity, diet and epigenetic mechanisms paves way for declining physical activity levels spontaneously, further leading to energy imbalance and reduced total energy expenditure, finally directing the path for expansion of obesity trends [7] [8]. Over the last few decades incidence rate of excess body weight and obesity have augmented considerably. Worldwide, over $30 \%$ of the total adult population constituting to be around 1 billion in number has been categorized as obese, currently. It signals towards the fact that in the forthcoming years such drift will not suspend at all rather it is expected to continue unabatedly [9]. Scientific investigations have revealed that the prevalence of obesity is furthermore among children living in households where both their parents are overweight or obese. Even if one of their parents is obese then the chance for such children to become obese adults increases dramatically by $30 \%$ than the non-obese; and it also increases by 17 times for individuals between 15 to 17 years of age [10] [11].

Several studies have reported alarmingly upward trends for obesity particularly among females living in Delhi [12] [13] [14] using body composition (densitometric) and anthropometric techniques. Here, it becomes significant to understand that the perils associated with onset of a disorder can be determined using cases of family history that has a significant role to play in predicting and diagnosing a disease. Family history is a complex association between hereditary factors, environment and behavioral regime being shared on a larger degree than just with the general population. Yet over some of these factors even science is 
helpless at times to alter them in eugenics [1] [15]. Nonetheless, focusing on the behavioral facets-taking healthier diet and maintaining sufficient physical activity levels, the basic of all, are highly recommended strategies for taming obesity [16]. Delhi being a metropolitan city is more prone to lifestyle problems and exposed to western culture. Contemplating over these lines present study attempts to concentrate on Delhi population facing such problems and assess the extent of risk related to family history of obesity for being obese over the forthcoming generations among a small subset of adolescent females of Delhi.

\section{Methodology}

The sample for present cross-sectional study consisted of 444 females aged between 18 - 22 years. All participants were under-graduate students of Daulat Ram College, affiliated with University of Delhi. Data was collected using multi stratified sampling. Socio-demographic information and other parameters related to lifestyle were gathered using a self-administered proforma from all participants that included sections on demography, socioeconomic status, lifestyle/behavioural regime and first-degree family history for obesity. However, before administering the proforma, informed written consent was taken from all the participants who wished to volunteer for the study after gaining insights about its aim. Ethical clearance was obtained from the principal of the college. Anthropometric and physiological measurements were recorded using standard techniques recommended by Weiner \& Lourie (1969) [17] and Shavers (1982) [18] respectively.

Blood pressure was recorded in a relaxed position with arm placed at heart level using Omron blood pressure monitor. For stature, crossbar of anthropometer was raised up to height of participant touching the vertex, in mid sagital plane when head is in Frankfurt Horizontal Plane while, weight was measured using Omron Karada Scan (Model HBF-362). Waist circumference was measured at the midpoint between the lower margin of the least palpable rib and the top of the iliac crest, using a stretch resistant tape. Hip circumference was measured around the widest portion of the buttocks, with the tape positioned parallel to the floor. For all measurements, every participant was asked to stand with feet close together, arms raised by the sides and body weight being evenly distributed, with minimum clothing. Obesity related conditions were described based on BMI [19], WHR [20], WHtR [21] and waist circumference [22] recommended over an international basis. All indices were further calculated using the previously recorded measurements.

Family history for obesity was described based on responses specified by participants as "yes" or "no", since self-reported family history of the condition as a recollection of diagnosis among first-degree relatives is easy to ascertain [1], however biases due to differential recall could not be eliminated. Data analysis was carried out using descriptive, inferential statistics and cross-tabulation in SPSS 20.0. Student's t-test and Chi-square test were used to work out homogene- 
ity and statistical significance between groups. Odds ratios were calculated for multinomial logistic regression tests to assess and estimate the impact of independent variables on dependent ones. Level of significance was set at $\mathrm{p}<0.05$.

\section{Results}

Baseline characteristics of participants are depicted in Table 1 and Figures 1-3

Table 1. Baseline characteristics of participants.

\begin{tabular}{|c|c|c|}
\hline \multicolumn{2}{|c|}{ Characteristics } & \multirow{2}{*}{$\begin{array}{c}\text { Frequency } \\
\mathrm{N}(\%)\end{array}$} \\
\hline Father's occupation & Not alive & \\
\hline & Farming & $39(8.8)$ \\
\hline & Service & $260(58.6)$ \\
\hline & Business & $125(28.2)$ \\
\hline & Retired & $8(1.8)$ \\
\hline \multirow[t]{4}{*}{ Mother's occupation } & Not alive & $3(0.7)$ \\
\hline & Service & $81(18.2)$ \\
\hline & Business & $7(1.6)$ \\
\hline & Homemaker & $353(79.5)$ \\
\hline \multirow[t]{2}{*}{ Diet pattern } & Vegetarian & $262(59.0)$ \\
\hline & Non-vegetarian & $182(41.0)$ \\
\hline \multirow[t]{2}{*}{ Food type } & Home-made & $197(44.4)$ \\
\hline & Hostel/PG & $247(55.6)$ \\
\hline \multirow[t]{2}{*}{ Whether take 3 meals } & Yes & $291(65.5)$ \\
\hline & No & $153(34.5)$ \\
\hline \multirow[t]{2}{*}{ Breakfast status } & Regular & $266(59.9)$ \\
\hline & Irregular & $178(40.1)$ \\
\hline \multirow[t]{3}{*}{ If skip any meal } & Yes & $212(47.7)$ \\
\hline & Sometimes & $101(22.7)$ \\
\hline & No & $131(29.5)$ \\
\hline \multirow[t]{6}{*}{ Status of eating junk food } & Daily & $48(10.8)$ \\
\hline & Twice a week & $59(13.3)$ \\
\hline & Once a week & $183(41.2)$ \\
\hline & Fortnightly & $17(3.8)$ \\
\hline & Monthly & $61(13.7)$ \\
\hline & Occasionally & $76(17.1)$ \\
\hline \multirow[t]{3}{*}{ Physical activity level } & Daily/weekly & $186(41.9)$ \\
\hline & Fortnightly/occasionally & $170(38.3)$ \\
\hline & Not at all & $88(19.8)$ \\
\hline \multirow[t]{2}{*}{ Family history for obesity } & Yes & $103(23.2)$ \\
\hline & No & $341(76.8)$ \\
\hline
\end{tabular}




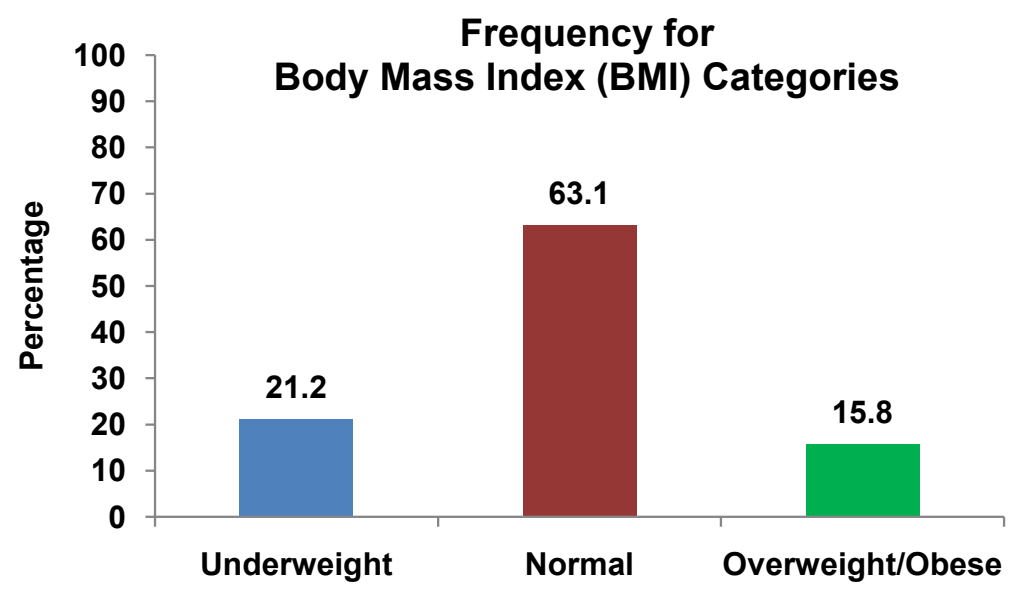

Figure 1. Distribution of participants in different BMI categories.

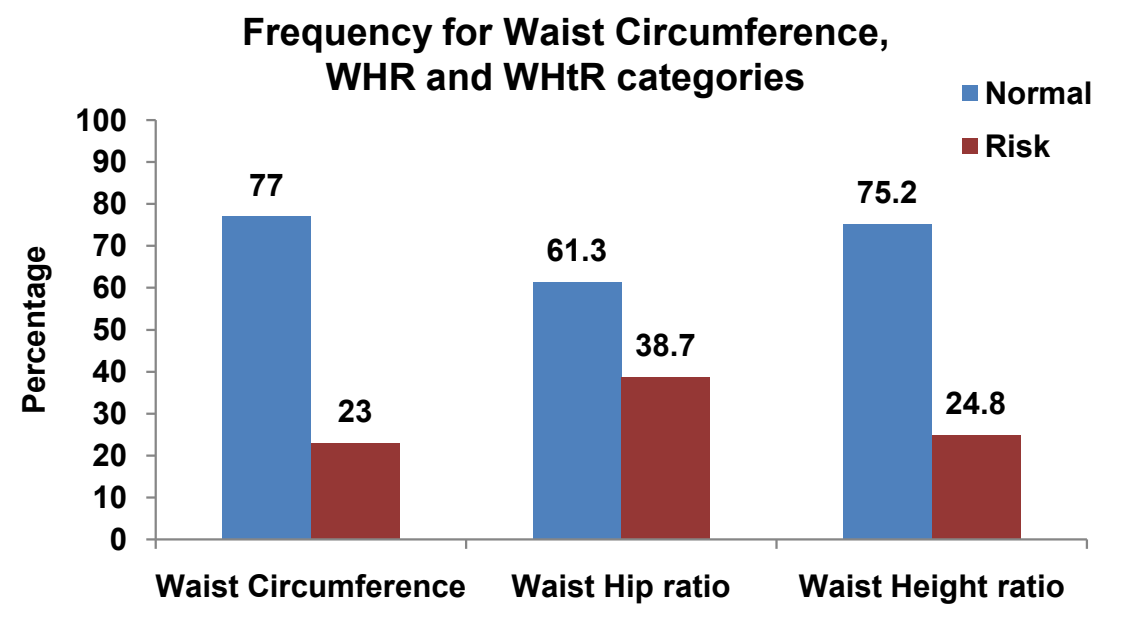

Figure 2. Distribution of participants in different adiposity indices categories.

Frequency for SBP and DBP categories

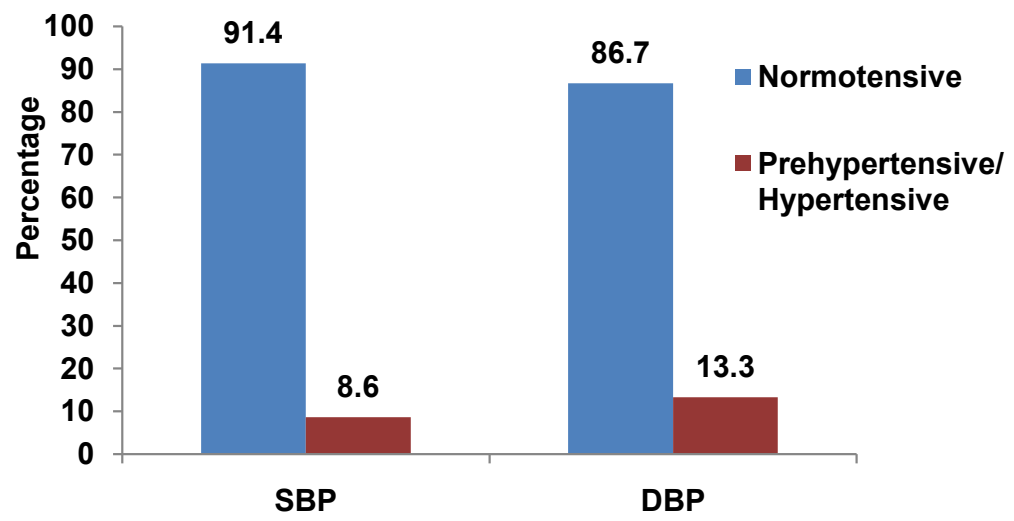

Figure 3. Distribution of participants according to blood pressure categories. SBP: Systolic Blood Pressure, DBP: Diastolic Blood Pressure.

which includes occupational profile of their parents, diet patterns, physical activity level, adiposity indices and markers along with history for obesity. Busi- 
ness $(28.2 \%)$, service $(58.6 \%)$ and farming (8.8\%) were majorly practiced occupations among the fathers while majority mothers were homemakers $(79.5 \%)$ followed by those who were either service-women $(18.2 \%)$ or business-women (1.6\%). Vegetarian diet being consumed mainly away from home was key trend amongst these college going girls of Delhi recruited for study as per the recorded frequencies. Also, taking three meals a day, with regular intake of breakfast, without skipping any meal and having junk food at least once a week were some of the key tendencies seen among them. Physical activity was chiefly a regular to occasional matter for them. $23.2 \%$ of the total participants responded to have a positive family history for obesity. Participants who are normal for adiposity/physiological indicators are much higher than their counterparts. However, those at risk based on waist hip ratio constituted the highest percentage than in the other adiposity/physiological parameters.

A positive family history of obesity has a notably huge association with exalted body age, total body fat percentage, body mass index, waist circumference, waist hip ratio and waist height ratio, shown in Table 2 (positive and negative history of obesity in family were coded 1 and 2, respectively). From Table 3, participants retaining a history for obesity in family demonstrated a higher mean body age, 28.8 years compared with others who did not have a familial association with obesity (24.8 years). Mean body weight was also witnessed to be more among the former than the latter $(57.5 \mathrm{~kg}$ vs $52.1 \mathrm{~kg}) .76 .1 \mathrm{~cm}$ was recorded to be the mean waist circumference for persons who had reported a family history

Table 2. Correlation between family history for obesity and adiposity measures.

\begin{tabular}{ccccccc}
\hline $\begin{array}{c}\text { Family history of } \\
\text { obesity }\end{array}$ & Body age & Total fat \% & BMI & WC & WHR & WHtR \\
\hline & $-0.209^{* * *}$ & $-0.142^{* *}$ & $-0.217^{* * *}$ & $-0.142^{* *}$ & -0.052 & $-0.148^{* *}$ \\
\hline
\end{tabular}

${ }^{\star *} \mathrm{p}<0.01,{ }^{* * *} \mathrm{p}<0.001$

Table 3. Mean, standard deviation and t-test values for body age, anthropometric measurements, total fat percentage and adiposity indices as per family history for obesity.

\begin{tabular}{cccc}
\hline & \multicolumn{2}{c}{ Family history for obesity } & \\
\cline { 2 - 3 } Measures & \multicolumn{2}{c}{ Nos } & t-test value \\
\cline { 2 - 3 } & \multicolumn{2}{c}{ Mean \pm S.D. } \\
\hline Body age & $28.8 \pm 8.61$ & $24.8 \pm 7.22$ & $4.685^{* * *}$ \\
Body weight & $57.3 \pm 10.53$ & $52.1 \pm 9.36$ & $4.821^{* * *}$ \\
Waist circumference & $76.1 \pm 10.53$ & $72.6 \pm 9.10$ & $3.324^{* *}$ \\
Total fat \% & $30.7 \pm 5.20$ & $28.8 \pm 5.08$ & $3.267^{* *}$ \\
BMI & $23.0 \pm 3.89$ & $21.1 \pm 3.43$ & $4.902^{* * *}$ \\
WHR & $0.79 \pm 0.062$ & $0.78 \pm 0.064$ & 1.013 \\
WHtR & $0.48 \pm 0.066$ & $0.46 \pm 0.056$ & $3.144^{* *}$ \\
\hline
\end{tabular}

${ }^{* *} \mathrm{p}<0.01,{ }^{* * *} \mathrm{p}<0.001$ 
of obesity, and $72.6 \mathrm{~cm}$ for the rest. $30.7 \%$ compared to $28.8 \%$ was mean total body fat percentage among the two groups, respectively. Other indices (used to define adiposity) also documented similar trend as the other talked about parameters in the two groups for family history of obesity-BMI (23.0 vs 21.1), WHR (0.79 vs 0.78$)$, WHtR (0.48 vs 0.46$)$. All these results (except for waist hip ratio) held a high statistical significance. It could be deduced that persons holding a history for obesity in family are far more obese or are under constant risk for being so in near future.

As per Table 4, in overweight/obese (for body mass index) class from both categories, participants ascertaining their family as having cases of obesity in past had majority participants $(27.1 \%)$ than the ones who had not reported any such history $(12.4 \%)$, with high statistical significance $(\mathrm{p}<0.001)$. Considering the group at risk for high waist height ratio, participants who reported such family history were comparatively more in proportion (25.9\% vs $21.4 \%$ ), among both the categories of family history for obesity at $\mathrm{p}<0.01$. On similar lines, participants at risk for waist circumference and waist hip ratio were more in fraction among those with a family history of obesity compared to their counterparts (for statistical non-significance).

From Table 5, it could be noted that odds ratio was significantly higher for WHtR $(\mathrm{OR}=3.1 ; \mathrm{CI}=1.28,7.66)$ and highest for body mass index $(\mathrm{OR}=2.3$; CI $=1.32,3.99)$ in association with family history reported for obesity. This is suggestive of the fact that positive incidences of obesity among family members in past leads to elevated adiposity in forthcoming generations. However, same could

Table 4. Distribution of participants according to anthropometric characteristics and family history status for obesity.

\begin{tabular}{|c|c|c|c|c|c|c|}
\hline \multicolumn{7}{|c|}{ FAMILY HISTORY FOR OBESITY } \\
\hline & \multicolumn{2}{|c|}{ Yes } & \multicolumn{2}{|c|}{ No } & \multirow[b]{3}{*}{ Total } & \multirow[b]{3}{*}{$x^{2}$ value } \\
\hline & \multicolumn{2}{|c|}{$\mathrm{N}=103(23.2 \%)$} & \multicolumn{2}{|c|}{$\mathrm{N}=341(76.8 \%)$} & & \\
\hline & $\mathrm{N}$ & $\%$ & $\mathrm{~N}$ & $\%$ & & \\
\hline \multicolumn{7}{|l|}{ BMI } \\
\hline Underweight & 12 & 11.7 & 82 & 24.0 & 94 & \multirow{3}{*}{$16.91^{\star * *}$} \\
\hline Normal weight & 63 & 61.2 & 217 & 63.6 & 280 & \\
\hline Overweight/obese & 28 & 27.1 & 42 & 12.4 & 70 & \\
\hline \multicolumn{7}{|l|}{ Waist circumference } \\
\hline Normal & 72 & 69.9 & 270 & 79.2 & 342 & \multirow{2}{*}{3.85} \\
\hline Risk & 31 & 30.1 & 71 & 20.8 & 102 & \\
\hline \multicolumn{7}{|l|}{ WHR } \\
\hline Normal & 61 & 59.2 & 211 & 61.9 & 272 & \multirow{2}{*}{0.235} \\
\hline Risk & 42 & 40.8 & 130 & 38.1 & 172 & \\
\hline \multicolumn{7}{|l|}{ WHtR } \\
\hline Normal & 66 & 64.1 & 268 & 78.6 & 334 & \multirow{2}{*}{$8.942^{* *}$} \\
\hline Risk & 37 & 25.9 & 73 & 21.4 & 110 & \\
\hline
\end{tabular}


Table 5. Test of logistic regression for family history of obesity and various adiposity markers.

\begin{tabular}{cccc}
\hline Variables & Categories & Exp (B) & CI (95\%) \\
\hline \multirow{2}{*}{ Body mass index } & Underweight & $0.504^{*}$ & $(0.25,0.98)$ \\
& Overweight & $2.296^{* *}$ & $(1.32,3.99)$ \\
Waist circumference & Normal weight & $0^{\mathrm{a}}$ & - \\
& Risk & 0.764 & $(0.30,1.27)$ \\
Waist hip ratio & Normal & $0^{\mathrm{a}}$ & - \\
& Risk & 0.712 & $(0.39,1.27)$ \\
Waist height ratio & Normal & $0^{\mathrm{a}}$ & - \\
& Risk & $3.143^{*}$ & $(1.28,7.66)$ \\
\hline
\end{tabular}

$0^{\mathrm{a}}$ : Reference category (Normal); Dependent category: Body mass index, waist circumference, waist hip ratio, waist height ratio; Reference category: No family history for obesity.

not be said with considerable substantiation to be true for waist circumference and waist hip ratio.

\section{Discussion}

Increased incidence of non-communicable disorders in developing nations is an outcome of cumulative effect of demographic transitions, such as increase in life expectancy, increase in proportion of the older age group population; and epidemiological transition like availability of immunizations and treatment for infectious diseases which in turn reduces the immediate impact of many such diseases. On the other hand, urbanization and westernization-related changes in lifestyle, such as dietary patterns, smoking and alcohol consumption practices, physical inactivity and increased levels of stress, lead to an increased threat for the advent of chronic, non-communicable diseases [1] [23].

One of the most rapidly growing public health problems in terms of its prevalence, costs and health effects is obesity that is affecting an increasingly larger number of countries worldwide [13]. Obesity pandemic is a much more common, demanding for vital attention, than other non-communicable diseases [24]. However, currently childhood obesity has become a major public health issue [25] [26]. Gravity of increased prevalence of childhood obesity could be demonstrated from the fact-this will be the first generation in which children would die before their parents in significant numbers [13] [27]. Future decades would witness an increase in the ratio of overweight and obese individuals than the normal weight population, if the prevalence rate of obesity continues to amplify. An effective remedy for obesity requires detection and modification of preventive and causative etiological vectors [13]. Prevalence rate estimation of obesity is instrumental for execution of future intervention plans for its prevention and control [24]. 
Obesity is a multifactorial condition with a strong lifestyle-allied influence. It is determined by environmental as well as genetic factors, triggering several other diseases [25] [28] [29]. Familial history has been identified as a chief risk factor for several chronic diseases of public health significance, including obesity. But not much is known about the accuracy of self-reported familial history, particularly self-reported familial history of obesity. However, such information could be of immense significance for using in genetic studies and others intended to understand disparity between participants with and without family history of obesity. Self-reported measure of family history (here for obesity) is beneficial in terms of practicality as a low-cost method, valid over a larger proportion of individuals [3].

It has been illustrated in some studies that there exists "familial aggregation" in familial correlations of obese/overweight state during early days of life [30] whereby daughters are more likely to be inflicted upon by parental indices of adiposity than sons [14]. Consistent with these lines, a positive history in family for obesity cases has been highlighted in the present study to be one of the major diagnostic risk factors for the onset of weight gain, equally suggested by many other studies [1] [2] [3]. Present work could be taken as an opportunity for incorporating interventional policies intended for health promotion and prevention of several life-threatening non-communicable diseases, obesity being one of them. Positive familial history of obesity has demonstrated a considerable association with an elevated age of body, body fat percentage (in total), and with all other obesity indices, including waist circumference, proven by descriptive statistics and inferential statistics directed over the data used for this study. It could be realized that cases of history for obesity in family have made the following generations far more obese/highly vulnerable for being so. It denotes that genetic influence being necessarily predominantly pervasive may infest across virtually all phenotypic instances, or are likely to manifest through different interplay with environment. Or according to another possibility, the nature-nurture correlation by which an individual's own behavior, that again gets partly impacted by genes can influence exposures to environmental risks either directly or by inducing risk-imposing behavior on other members in a family [31].

Involving family-units would be a crucial step in this process of identification of the patient and their immediate family members highly vulnerable for becoming patients themselves. However, family-ties are likely to get loosen with progressing westernization and urbanization. But for the countries that are relatively smaller and cohesive, this process would take time. Households high-at risk for developing obese status further highlighted by stronger family for the same require interventions to promote lifestyle changes in their diet and physical activity, as a rational strategy to manage its incidence and prevention [1]. Even the work preceding this currently presented piece suggests at cultivating healthy eating habits and other standard practices for stimulating an enduring lifestyle. This provides an escape from triggering the chances of progression of obesity, mainly of abdominal/central type [32]. 
For an individual or a group to reject or embrace lifestyle changes role of family ties and coherence could be imperative to note. The risk for undergoing obesity multiplies several times when accompanied with low level of physical activity among family members. This indicates that modification of diet and activity plans could be effective interventions. Also, having witnessed the burden of such maladies within their family, folks are more likely to be motivated to modify their behavioral patterns such that their motivation for behavior change would, therefore be widen-up than that among the general population. However, a behavioural change might be impossible to implement and consolidate if it is not accepted as a family commitment in a society where family-ties are very strong, and most people eat from communal family food bowls [1]. While on government-led intervention front, it has been suggested that decentralization of care could help to enhance control over non-communicable diseases [33].

\section{Conclusion}

Present study corroborated the undeniable vulnerability for increased weight gain on familial lines, thus implying the need towards comprehensive edification of society about the same. Also, assessment of abdominal adiposity in relation to history for general obesity is instrumental for predicting the same, as suggested in the current study. This brings us to the conclusion that shifting to standard lifestyle patterns, possibly during earlier ages of life especially among those bearing a family history of obesity is the utmost demand of hour, since genetic predisposition could not be altered at all in this regard over a wider scale.

\section{Acknowledgements}

We would like to express our deep gratitude for our principal, Dr. Savita Roy for her unfaltered support in conducting the study and Dr. Satwanti Kapoor for her critical analysis and suggestions. We would also like to express our sincere gratitude for Prof. Alo Nag for being a source of constant motivation, inspiration and encouragement throughout the period of study. We would also like to thank volunteers for their consent and participation in the study.

\section{Conflicts of Interest}

The authors declare no conflicts of interest regarding the publication of this paper.

\section{References}

[1] Van der Sande, M.A., Walraven, G.E., Milligan, P.J., Banya, W.A., Ceesay, S.M., Nyan, O.A. and McAdam, K.P. (2001) Family History: An Opportunity for Early Interventions and Improved Control of Hypertension, Obesity and Diabetes. Bulletin of the World Health Organization, 79, 321-328.

[2] Saunders, T.J., Tremblay, M.S., Mathieu, M.Ė., Henderson, M., O’Loughlin, J., Tremblay, A., Chaput, J.P. and Quality Cohort Research Group (2013) Associations of Sedentary Behavior, Sedentary Bouts and Breaks in Sedentary Time with Cardi- 
ometabolic Risk in Children with a Family History of Obesity. PLoS ONE, 8, e79143. https://doi.org/10.1371/journal.pone.0079143

[3] Paradis, A.M., Pérusse, L., Godin, G. and Vohl, M.C. (2008) Validity of a Self-Reported Measure of Familial History of Obesity. Nutrition Journal, 7, 27. https://doi.org/10.1186/1475-2891-7-27

[4] Mungreiphy, N.K., Dhall, M., Tyagi, R., Saluja, K., Kumar, A., Tungdim, M.G., Sinha, R., Rongmei, K.S., Tandon, K., Bhardwaj, S. and Kapoor, A.K. (2012) Ethnicity, Obesity and Health Pattern among Indian Population. Journal of Natural Science, Biology, and Medicine, 3, 52-59. https://doi.org/10.4103/0976-9668.95955

[5] Pongen, I., Dhall, M. and Kapoor, S. (2016) Occupation, Physical Fitness and Adiposity Markers among Security Guards and Students of Delhi University. Health, 8, 978-985. https://doi.org/10.4236/health.2016.810101

[6] Dhall, M. and Kapoor, S. (2018) Dynamism of Physical Activity and Lifestyle Diseases. Dhanraj Book House, Delhi, India.

[7] Eisenmann, J.C. (2006) Insight into the Causes of the Recent Secular Trend in Pediatric Obesity: Common Sense Does Not Always Prevail for Complex, Multi-Factorial Phenotypes. Preventive Medicine, 42, 329-335. https://doi.org/10.1016/j.ypmed.2006.02.002

[8] Kapoor, S., Sinha, R., Tandon, K., Gupta, S., Bhasin, P., Verma, D. and Dhall, M. (2013) Development of Obesity over Four Decades among North Indian Females. Eurasian Journal of Anthropology, 4, 16-22.

[9] Wiklund, P. (2016) The Role of Physical Activity and Exercise in Obesity and Weight Management: Time for Critical Appraisal. Journal of Sport and Health Science, 5, 151-154. https://doi.org/10.1016/j.jshs.2016.04.001

[10] Agha, M. and Agha, R. (2017) The Rising Prevalence of Obesity: Part A: Impact on Public Health. International Journal of Surgical Oncology, 2, e17.

[11] Government Office for Science (2009) Tackling Obesities: Future Choices-Modelling Future Trends in obesity \& Their Impact on Health. www.bis.gov.uk/assets/bispartners/foresight/docs/obesity/14.pdf

[12] Kapoor, S., Singh, I.P. and Bharadwaj, H. (1980) Body Fat and Fat-Free Mass Assessed by Densitometric and Anthropometric Techniques in Adult Indian Women. Zeitschrift fuer Morphologie und Anthropologie, 71, 274-284.

[13] Sinha, R. and Kapoor, S. (2006) Parent-Child Correlation for Various Indices of Adiposity in an Endogamous Indian Population. Collegium Antropologicum, 30, 291-296.

[14] Gupta, S. and Kapoor, S. (2012) Gender Differences in Familial Aggregation of Adiposity Traits in Aggarwal Baniya Families. Eurasian Journal of Anthropology, 2, 85-95.

[15] Watt, G.C.M. (1994) Strengths and Weaknesses of Family Studies of High Blood Pressure. Journal of Human Hypertension, 8, 327-328.

[16] Rao, G.H.R. (2018) Fitness, Lifestyle Changes, and Wellness: Cardiometabolic Health. Cardiology, 2, Article ID: 000132.

[17] Weiner, J.S. and Lourie, J.A. (1969) Human Biology. A Guide to Field Methods. IBP Handbook, No. 9. Blackwell Scientific Publishers, Oxford.

[18] Shavers, L.G. (1982) Essentials of Exercise Physiology. Surjeet Publications, Delhi, India.

[19] Who, E.C. (2004) Appropriate Body-Mass Index for Asian Populations and Its Implications for Policy and Intervention Strategies. Lancet, 363, 157-163. 
https://doi.org/10.1016/S0140-6736(03)15268-3

[20] Willett, W.C., Dietz, W.H. and Colditz, G.A. (1999) Guidelines for Healthy Weight. New England Journal of Medicine, 341, 427-434. https://doi.org/10.1056/NEJM199908053410607

[21] Ashwell, M. and Hsieh, S.D. (2005) Six Reasons Why the Waist-to-Height Ratio Is a Rapid and Effective Global Indicator for Health Risks of Obesity and Its Use Could Simplify the International Public Health Message on Obesity. International Journal of Food Sciences and Nutrition, 56, 303-307. https://doi.org/10.1080/09637480500195066

[22] Alberti, K.G.M.M., Eckel, R.H., Grundy, S.M., Zimmet, P.Z., Cleeman, J.I., Donato, K.A., Fruchart, J.C., James, W.P.T., Loria, C.M. and Smith Jr., S.C. (2009) Harmonizing the Metabolic Syndrome: A Joint Interim Statement of the International Diabetes Federation Task Force on Epidemiology and Prevention. National Heart, Lung, and Blood Institute, American Heart Association, World Heart Federation, International Atherosclerosis Society, and International Association for the Study of Obesity. Circulation, 120, 1640-1645. https://doi.org/10.1161/CIRCULATIONAHA.109.192644

[23] Dua, S., Bhuker, M., Sharma, P., Dhall, M. and Kapoor, S. (2014) Body Mass Index Relates to Blood Pressure among Adults. North American Journal of Medical Sciences, 6, 89-95. https://doi.org/10.4103/1947-2714.127751

[24] Reilly, J.J., El-Hamdouchi, A., Diouf, A., Monyeki, A. and Somda, S.A. (2018) Determining the Worldwide Prevalence of Obesity. The Lancet, 391, 1773-1774. https://doi.org/10.1016/S0140-6736(18)30794-3

[25] Reuter, C.P., Burgos, M.S., Bernhard, J.C., Tornquist, D., Klinger, E.I., Borges, T.S., Renner, J.D.P., Valim, A.R.D.M. and Mello, E.D.D. (2016) Association between Overweight and Obesity in Schoolchildren with rs9939609 Polymorphism (FTO) and Family History for Obesity. Jornal de Pediatria, 92, 493-498. https://doi.org/10.1016/j.jped.2015.11.005

[26] Cecil, J.E., Tavendale, R., Watt, P., Hetherington, M.M. and Palmer, C.N. (2008) An Obesity-Associated FTO Gene Variant and Increased Energy Intake in Children. New England Journal of Medicine, 359, 2558-2566. https://doi.org/10.1056/NEJMoa0803839

[27] Wee, C.C., Phillips, R.S., Legedza, A.T., Davis, R.B., Soukup, J.R., Colditz, G.A. and Hamel, M.B. (2005) Health Care Expenditures Associated with Overweight and Obesity among US Adults: Importance of Age and Race. American Journal of Public Health, 95, 159-165. https://doi.org/10.2105/AJPH.2003.027946

[28] De Luis, D.A., Aller, R., Conde, R., Izaola, O., De la Fuente, B., González Sagrado, M., Primo, D. and Ruiz Mambrilla, M. (2012) Relación del polimorfismo rs 9939609 del gen FTO con factores de riesgo cardiovascular y niveles de adipocitoquinas en pacientes con obesidad mórbida. Nutrición Hospitalaria, 27, 1184-1189.

[29] Lima, W.A., Glaner, M.F. and Taylor, A.P. (2010) Fenótipo da gordura, fatores associados e o polimorfismo rs9939609 do gene FTO. Revista Brasileira de Cineantropometria e Desempenho Humano, 12, 164-72.

[30] Keane, E., Layte, R., Harrington, J., Kearney, P.M. and Perry, I.J. (2012) Measured Parental Weight Status and Familial Socio-Economic Status Correlates with Childhood Overweight and Obesity at Age 9. PLOS ONE, 7, e43503. https://doi.org/10.1371/journal.pone.0043503

[31] Owen, M.J. (2006) Genes and Behavior: Nature-Nurture Interplay Explained by Michael Rutter. Blackwell, Oxford, 272 p. 
[32] Mangla, A.G., Dhamija, N., Gupta, U. and Dhall, M. (2019) Lifestyle Trends and Obesity among College Going Girls of Delhi. Health, 11, 201-210. https://doi.org/10.4236/health.2019.112018

[33] Coleman, R., Gill, G. and Wilkinson, D. (1998) Non Communicable Disease Management in Resource-Poor Settings: A Primary Care Model from Rural South Africa. Bulletin of the World Health Organization, 76, 633-640. 